\title{
Use of Streptococcus thermophilus for the in situ production of Y-aminobutyric acid-enriched fermented milk
}

\author{
Mei Han, ${ }^{1} \oplus$ Wen-yan Liao, ${ }^{2}$ Shen-mao Wu, ${ }^{2}$ Xia Gong,,${ }^{1 *}$ and Chen Bai ${ }^{1 *}$ (1) \\ ${ }^{1}$ Department of Food Quality and Safety, Shanghai Business School, Shanghai 200235, China \\ ${ }^{2}$ State Key Laboratory of Dairy Biotechnology, Technology Center Bright Dairy \& Food Co., Ltd., Shanghai 200436, China
}

\begin{abstract}
$\gamma$-Aminobutyric acid (GABA) is a potentially bioactive ingredient with health-promoting properties that is added to functional foods. Streptococcus thermophilus was selected to produce naturally GABA-enriched fermented milk. This strain can yield a GABA concentration of $2.8 \mathrm{~g} / \mathrm{L}$ after a 48 -h fermentation. In the presence of $1 \mathrm{~g} / \mathrm{L}$ food-grade casein hydrolysate as a nitrogen source, $S$. thermophilus yielded GABA concentrations as high as $5.4 \mathrm{~g} / \mathrm{L}$ or even $8.3 \mathrm{~g} / \mathrm{L}$ when cocultured with Lactobacillus rhamnosus. In other words, both of these added conditions promoted GABA enrichment. The GABA dose achieved with fermented milk was comparable to the doses of commercially available GABA supplements. Additionally, the in situ use of $S$. thermophilus to produce GABA-enriched fermented milk was cost effective. The complete genomic sequence of $S$. thermophilus GABA has been published and will be highly useful to other researchers studying the regulation of genes related to GABA accumulation. In conclusion, the $S$. thermophilus GABA-producing strain reported herein represents a natural method for the production of fermented milk containing high GABA concentrations.
\end{abstract}

Key words: Streptococcus thermophilus $\gamma$-aminobutyric acid, $\gamma$-aminobutyric acid, nitrogen source, co-culture

\section{INTRODUCTION}

$\gamma$-Aminobutyric acid (GABA), a 4-carbon nonprotein-forming amino acid, acts as a major inhibitory neurotransmitter in the central nervous system and plays important roles in physiological functions (Abdou et al., 2006; Dyke et al., 2017; Sanchart et al., 2017). $\gamma$-Aminobutyric acid exerts hypotensive (Hayakawa et al., 2004; Watanabe and Washio, 2011; Suwanmanon and Hsieh, 2014), diuretic (Jakobs et al., 1993), and

Received April 24, 2019

Accepted September 3, 2019.

*Corresponding author: hanmei.baichen_sh@163.com tranquilizing effects (Okada et al., 2000; Wong et al., 2003) and has been classified as a health-promoting bioactive component in foods and pharmaceuticals ( $\mathrm{Li}$ and Cao, 2010). Therefore, GABA-rich traditional and functional foods were on sale all over the world.

Screening of microorganisms used in traditional foods can identify those that possess the capacity to produce GABA through fermentation. This pathway provides a convenient and efficient means of producing GABAenriched foods. Several microorganisms (Yokoyama et al., 2002; Lu et al., 2008; Yang et al., 2008; Sun et al., 2009; Di Cagno et al., 2010; Nejati et al., 2013; Wu et al., 2015; Brasca et al., 2016) generally regarded as safe, such as lactic acid bacteria (LAB), have been researched widely and applied to GABA production. However, these GABA-producing LAB are largely cultivated in synthetic or semisynthetic media (Komatsuzaki et al., 2005; Lu et al., 2008; Yang et al., 2008), and therefore procedures are needed to separate and purify GABA after fermentation. Additionally, the suitability of these strains for GABA production in fermented milk and yogurt has not yet been explored.

Streptococcus thermophilus is a commercially relevant starter used widely in the industrial production of yogurt. However, conventional strains of S. thermophilus largely lack the capacity for the high-yield production of GABA as a potentially bioactive component in foods and pharmaceuticals. In this study, we screened a highGABA-producing $S$. thermophilus strain and developed an in situ method for the production of GABA-enriched fermented milk. This $S$. thermophilus GABA strain exhibits great potential as a starter for the production of GABA-enriched fermented milk, cheese, and other functional fermented foods.

\section{MATERIALS AND METHODS}

\section{Isolation of GABA-Producing Strains and Gene Analysis}

Twenty different traditional koumiss dairy products collected in Xinjiang province (China) were used to isolate GABA-producing strains. After proper dilution, 
$100 \mu \mathrm{L}$ of sample was spread on M17 and de Man, Rogosa, and Sharpe (MRS), pH 4.5 plate to select $S$. thermophilus and Lactobacillus. Fifty strains of $S$. thermophilus and 50 strains of Lactobacillus were cultured in $1 \mathrm{~mL}$ of M17 or MRS broth as the seed. Then $0.2 \mathrm{~mL}$ of seed culture was switched to $10 \mathrm{~mL}$ of reconstituted skim milk (containing 10\% skim milk powder and 10 $\mathrm{g} / \mathrm{L}$ monosodium glutamate (MSG) sterilized at $105^{\circ} \mathrm{C}$ for $15 \mathrm{~min}$ ) for GABA accumulation. The production of GABA was determined by HPLC. The strain with the highest yield was named $S$. thermophilus GABA (preservation number: CGMCC 14810) isolated by Mei Han. It was subjected to genomic sequencing by Majorbio (Shanghai, China). The complete sequence has been published in the National Center for Biotechnology Information database (accession number: CP025399). The sequence corresponding to $\operatorname{gadB}$, which encodes glutamate decarboxylase $\beta$ (GAD), was determined from the whole-genomic sequence. Phylogenetic analysis of $S$. thermophilus GABA based on the complete genomes was done using software MEGA 7 (https:// www.megasoftware.net/).

\section{Preparation of GABA-Enriched Fermented Milk In Situ Via S. thermophilus GABA Culture}

Streptococcus thermophilus GABA (CGMCC no. 14810) was cultured in a $100-\mathrm{mL}$ flask containing 50 $\mathrm{mL}$ of M17 broth (Oxoid, Basingstoke, UK) at $37^{\circ} \mathrm{C}$ for $24 \mathrm{~h}$, which yielded approximately $9 \log$ viable cfu/ $\mathrm{mL}$. The culture was then centrifuged at $2,500 \times g$ for 30 min at $4^{\circ} \mathrm{C}$ to obtain a bacterial pellet, which was washed in sterile water and used to seed the fermentation reaction. The fermentation medium consisted of reconstituted skim milk (Brightdairy, Shanghai, China) containing MSG (Sigma-Aldrich, St. Louis, MO) and was sterilized at $105^{\circ} \mathrm{C}$ for $15 \mathrm{~min}$. The fermentation reaction was inoculated at a concentration of $2 \times 10^{6}$ $\mathrm{cfu} / \mathrm{mL}$ and incubated without shaking. All fermentation experiments were performed in triplicate.

\section{Detection and Quantification of GABA Production Using HPLC}

Fermented milk was centrifuged and filtered through a Millex-HA $0.22-\mu \mathrm{m}$ pore size filter to collect the supernatant. The concentration of GABA in the supernatant was analyzed using HPLC according to the dabsyl chloride (Sigma-Aldrich) derivatization method (Syu et al., 2008). The GABA reagent standard was purchased from Sigma-Aldrich.

Briefly, the determination of dabsyl-GABA was carried out by HPLC (Agilent 1200, Santa Clara, CA).
A reversed-phase column (Agilent ZORBAX SB-C18, $250 \mathrm{~mm} \times 4 \mathrm{~mm}, 5 \mu \mathrm{m}$ particle size) coupled with a C18 cartridge was used. The column temperature was maintained at $35^{\circ} \mathrm{C}$. The detection wavelength was 425 $\mathrm{nm}$. The composition of the optimized mobile phase was methanol $/ \mathrm{CH}_{3} \mathrm{COONa}$ solution $(0.045 \mathrm{~mol} / \mathrm{L}, \mathrm{pH}$ 4) $65: 35$. The mobile phase was filtered through a 0.22 $\mu \mathrm{m}$ filter membrane and degassed before use.

\section{Optimization of Conditions Required for a High GABA Yield}

The effects of different temperatures on GABA production were tested by culturing the bacteria in medium containing $10 \%$ skim milk powder and $10 \mathrm{~g} / \mathrm{L}$ MSG at 37 and $42^{\circ} \mathrm{C}$. The effects of different nitrogen sources were tested at $37^{\circ} \mathrm{C}$ in medium containing $10 \%$ (wt/wt) skim milk powder, $10 \mathrm{~g} / \mathrm{L}$ MSG, and one of the following: casein hydrolysate $(\mathbf{C H})$, yeast extract (YE), or soy protein hydrolysate (SH) (Oxoid).

The coculture characteristics were tested by inoculating medium containing 10\% (wt/wt) skim milk powder and $15 \mathrm{~g} / \mathrm{L}$ MSG simultaneously with Lactobacillus and $S$. thermophilus GABA at a $1: 1$ ratio $\left(10^{6} \mathrm{cfu} /\right.$ $\mathrm{mL}$ each). Lactobacilli are L. delbrueckii (Wecare-Bio, Jiangsu, China), L. rhamnosus (Wecare-Bio), L. helveticus (Danisco, New Century, KS), and L. paracasei (Chr. Hansen, Hørsholm, Denmark).

Viable colony-forming units of $S$. thermophilus GABA were tested using M17 agar (Oxoid) at $43^{\circ} \mathrm{C}$ for $48 \mathrm{~h}$ in aerobic conditions. Viable colony-forming units of Lactobacillus were tested using MRS agar $\mathrm{pH} 4.5$ (Oxoid), at $37^{\circ} \mathrm{C}$ for $48 \mathrm{~h}$ in anaerobic conditions.

\section{RESULTS AND DISCUSSION}

\section{Analysis of the S. thermophilus GABA gadB Sequence}

The GABA-producing ability of 100 strains isolated from Xinjiang koumiss (containing 50 strains of $S$. thermophilus and 50 strains of Lactobacillus) was tested by HPLC. Only $2 S$. thermophilus strains isolated from koumiss produced GABA when cultured in milk. The GABA-producing gene, gadB, was present in only 10 of the 50 S. thermophilus strains. The GAD system converts 1 molecule of glutamate into 1 molecule of GABA (Di Cagno et al., 2010). Therefore, a method based on the production of GABA from GAD via fermentation is considered a convenient and efficient screening method. In a previous study of 191 S. thermophilus strains, Brasca and colleagues found that only $20(10 \%)$ harbored $\operatorname{gadB}$. Of those 20, only 5 were capable of 


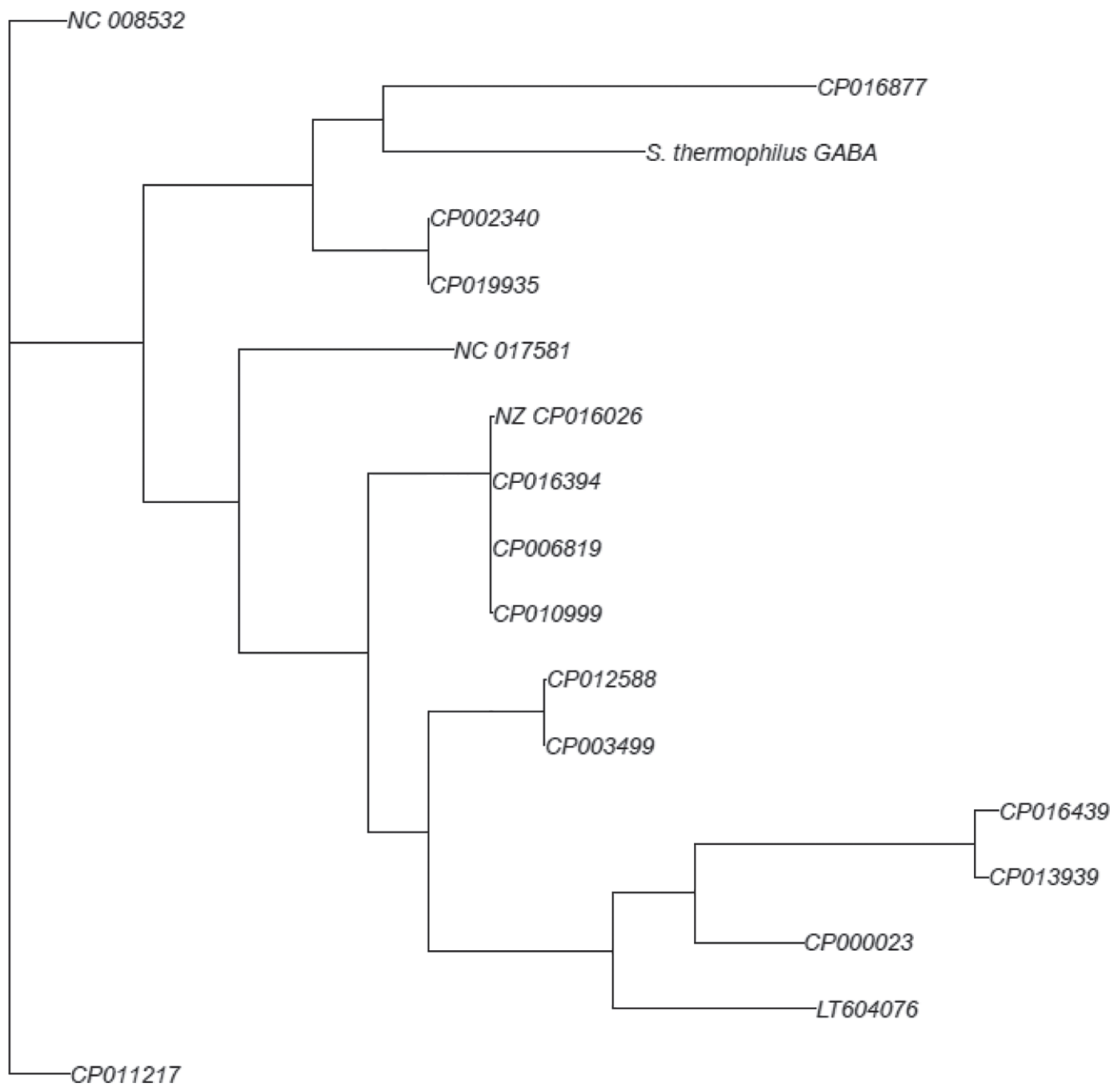

Figure 1. Phylogenetic analysis of Streptococcus thermophilus $\gamma$-aminobutyric acid (GABA) based on the complete genomes using software MEGA 7 (https://www.megasoftware.net/).

producing GABA in microfiltered pasteurized milk (Brasca et al., 2016). Therefore, only a small fraction of even gadB-positive $S$. thermophilus strains can produce GABA. The complete genomic sequences of $S$. thermophilus GABA (accession number: CP025399) and 16 other $S$. thermophilus strains have been published in the National Center for Biotechnology Information. A phylogenetic analysis based on the complete genomes of these 17 strains is shown in Figure 1. Notably, $S$. thermophilus GABA is most closely related to $S$. thermophilus CP016877. A Basic Local Alignment Search Tool (BLAST) analysis of the translational product of the gadB locus in $S$. thermophilus GABA and the other 16 strains revealed that only the strains GABA, ACADC 2 (accession number: LT604076.1), KLDS 3.1003 (accession number: CP016877.1), APC151 (accession number: CP019935.1), and ND03 (accession number: CP002340.1) harbor this locus. An AA sequence analysis of these 5 strains yielded almost identical gadB and glutamate/GABA antiporter (gadC) sequences. However, it is unknown whether these other gadB-positive strains actually make GABA. In addition, future genomic analysis of $S$. thermophilus GABA may reveal why this strain makes more GABA than other tested strains.

\section{Growth Dynamics and GABA Production During Milk Fermentation}

To produce GABA-fortified fermented milk, we cultivated $S$. thermophilus GABA in skim milk supplemented with MSG. Production of GABA was monitored using 
Table 1. Effect of temperature on viable count and $\gamma$-aminobutyric acid (GABA) production

\begin{tabular}{lcc}
\hline $\begin{array}{l}\text { Fermentation } \\
\text { condition }\end{array}$ & $\begin{array}{c}\text { Count } \\
\mathrm{cfu} / \mathrm{mL}\end{array}$ & $\begin{array}{c}\text { GABA } \\
\text { production }(\mathrm{g} / \mathrm{L} \pm \mathrm{SD})\end{array}$ \\
\hline $37^{\circ} \mathrm{C}$ & $5.2 \times 10^{8}$ & $1.1 \pm 0.1$ \\
$24 \mathrm{~h}$ & $2.1 \times 10^{9}$ & $2.8 \pm 0.2$ \\
$48 \mathrm{~h}$ & $1.2 \times 10^{9}$ & $3.4 \pm 0.2$ \\
$72 \mathrm{~h}$ & & \\
$42^{\circ} \mathrm{C}$ & $1.5 \times 10^{9}$ & $1.3 \pm 0.1$ \\
$24 \mathrm{~h}$ & $3.2 \times 10^{8}$ & $2.3 \pm 0.2$ \\
$48 \mathrm{~h}$ & $2.2 \times 10^{5}$ & $3.1 \pm 0.2$ \\
\hline $2 \mathrm{~h}$ & & \\
\hline
\end{tabular}

HPLC. Notably, temperature was among the most influential factors affecting bacterial growth, consistent with previous observations that this factor affects the fermentation time of exopolysaccharide production in S. thermophilus (Khanal and Lucey, 2018). The rate of milk acidification is a highly important technological factor in the manufacturing of fermented milk. Accordingly, the $\mathrm{pH}$ curves of GABA-fermented milk products were recorded during the fermentation process. Figure 2 demonstrates that the lag phases of $S$. thermophilus GABA decreased as the temperature increased, suggesting a strong inverse relationship. The acidification rate of milk also depended greatly on temperature, as this factor increased with increasing temperature. Our finding was consistent with a previous report by Haque and colleagues in which increasing fermentation temperature was shown to increase the rate at which the $\mathrm{pH}$ decreased (Haque et al., 2001). Moreover, the production of GABA was higher at $42^{\circ} \mathrm{C}$ than at $37^{\circ} \mathrm{C}$ during a 24-h fermentation period because of the rapid growth rate at high temperature, but decreased over longer periods ( 48 or $72 \mathrm{~h}$ ) due to more rapid bacterial death at the higher temperature (Table 1). Accordingly, we determined that $37^{\circ} \mathrm{C}$ is the optimal culture temperature for maximum GABA production. A change in the fermentation temperature would affect the production of GABA and lactic acid by S. thermophilus strains because the fermentation temperature affects both the growth rate and growth stress.

\section{Supplementation with Food-Grade Organic Nitrogen Promotes GABA Production}

Organic nitrogen sources are widely used to promote microbial growth during fermentation. Dave and Shah (1998) reported that although a 12 -h period was needed to reach a $\mathrm{pH}$ of 4.5 in control fermented milk incubated at $37^{\circ} \mathrm{C}$, this incubation time decreased to $9 \mathrm{~h}$ in a culture supplemented with $\mathrm{CH}$ or tryptone. Moreover, the inclusion of a low concentration of $\mathrm{YE}(0.1 \%)$ in liquid medium favored rapid growth and high viability in cultures of Rhizobium sp. (Skinner et al., 2010). Although nitrogen sources can be used to enhance the fermentation rate, these chemicals are unpalatable and are rarely added to fermented foods. Therefore, the nitrogen level must be controlled within an acceptable

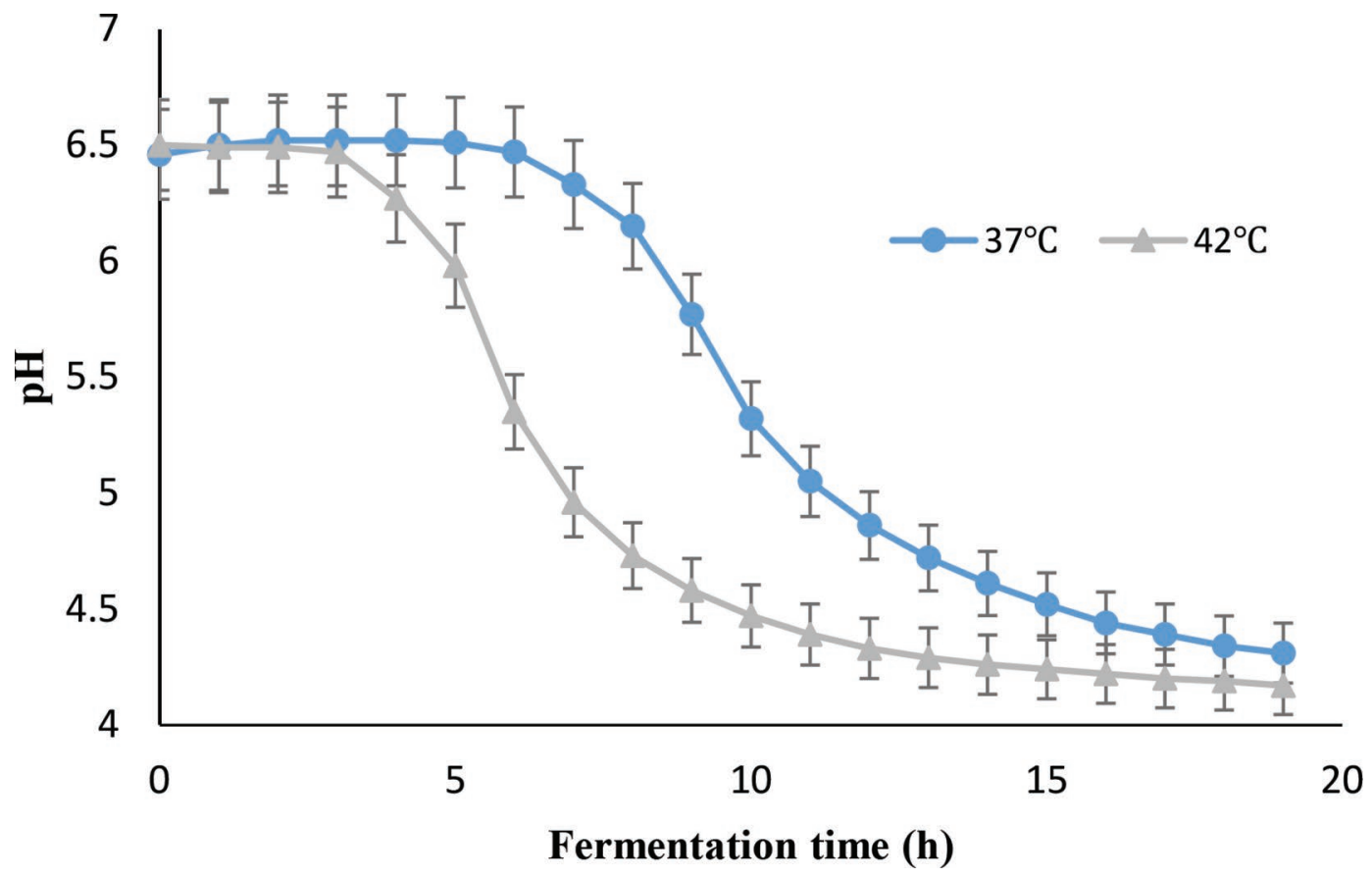

Figure 2. Effect of culture temperatures on pH changes at $37^{\circ} \mathrm{C}(\bullet)$ and $42^{\circ} \mathrm{C}(\boldsymbol{\Delta})$. Error bars indicate SD. 


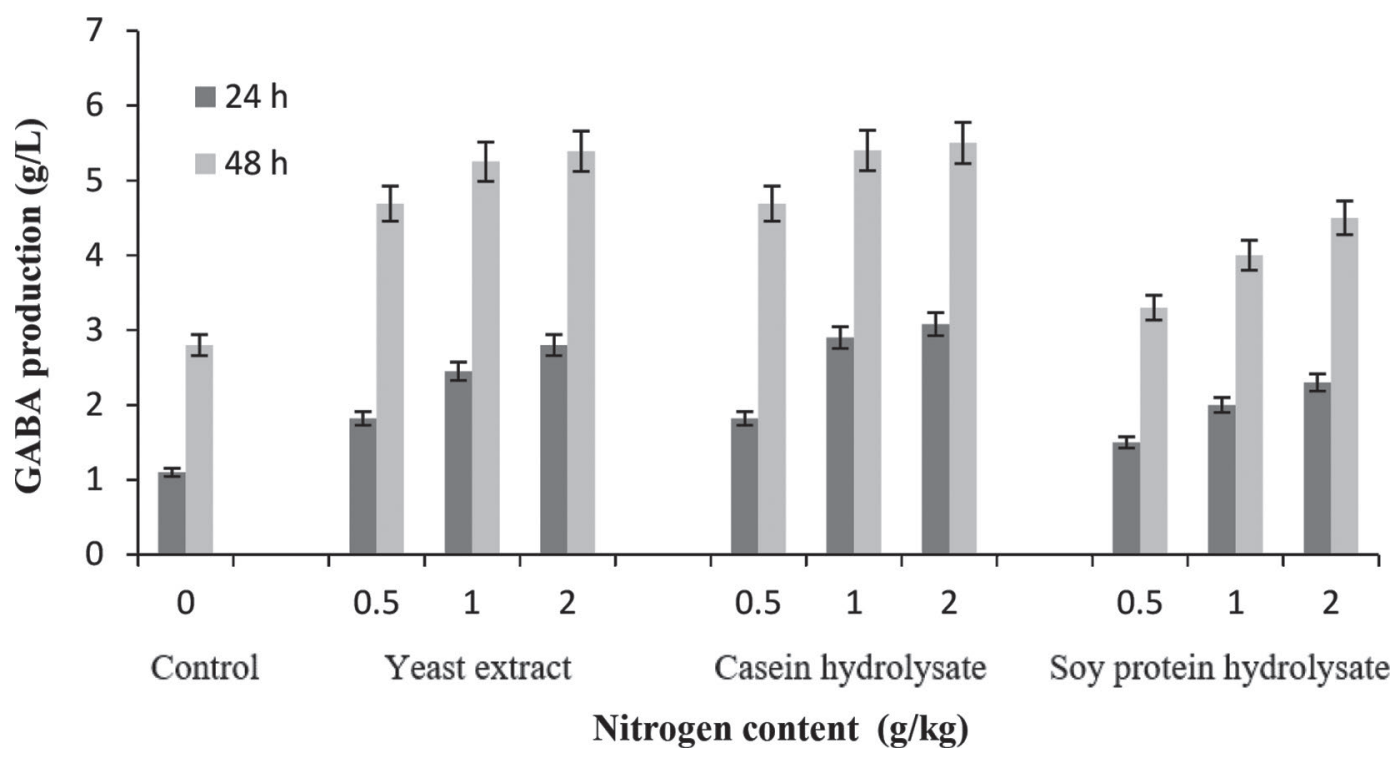

Figure 3. Effect of edible nitrogen content on the production of $\gamma$-aminobutyric acid (GABA). Yeast extract, casein hydrolysate, and soy protein hydrolysate were tested at the contention of $0.5,1$, and $2 \mathrm{~g} / \mathrm{kg}$ reconstituted milk after $24 \mathrm{~h}$ (black) and $48 \mathrm{~h}$ (gray) fermentation. Error bars indicate SD.

level, and the nitrogen source must be edible. Some food-grade organic nitrogen sources, such as $\mathrm{CH}$, YE, and SH, were tested. All 3 sources led to remarkable increases in bacterial growth and GABA production even at low concentrations. As shown in Figure 3, when $\mathrm{CH}$, $\mathrm{YE}$, and SH were tested at a concentration of $1 \mathrm{~g} / \mathrm{L}$, $\mathrm{CH}$ led to the highest GABA yield of $2.9 \mathrm{~g} / \mathrm{L}$ after a 24 -h fermentation. This represented a $160 \%$ increase in GABA production relative to the control. After a 48-h fermentation, the CH-supplemented culture produced a GABA yield of $5.4 \mathrm{~g} / \mathrm{L}$, representing a $93 \%$ increase over the control. These results support the use of $\mathrm{CH}$ as an effective edible nitrogen source in traditional foods.

\section{Coculture with Different LAB Strains to Produce GABA Yogurt}

In most countries, the term yogurt can only be applied legally to milk products fermented simultaneously using S. thermophilus and Lactobacillus delbrueckii (Han et al., 2014). The best example of mutualism during food processing involves the fermentation of yogurt by $S$. thermophilus and L. delbrueckii. The proto-cooperative process of yogurt fermentation enhances the growth rate and size of each bacterial population (Sieuwerts et al., 2010). These previously described interactions are trophic, wherein the species feed each other by producing formic acid, pyruvate, folate, long-chain fatty acids, ornithine, carbon dioxide, peptides, AA, and putrescine (Sieuwerts et al., 2010). Accordingly, we evaluated
GABA production in cocultures of $S$. thermophilus with different Lactobacillus strains.

Four different LAB strains (L. delbrueckii, L. rhamnosus, L. helveticus, and L. paracasei) were cocultured with $S$. thermophilus GABA, and the production of GABA-enriched fermented milk was evaluated. Although L. helveticus had a rapid acidification rate (Figure 4), this culture contained the lowest number of living cells after a 48-h fermentation (Table 2). Production of GABA was enhanced in all cocultures with Lactobacillus spp., with the weakest and strongest enhancement observed in cultures containing $L$. delbrueckii and $L$. rhamnosus, respectively. Notably, GABA production increased by $260 \%$ when $S$. thermophilus GABA was cocultured with L. rhamnosus for $48 \mathrm{~h}$ (Table 2). Using the 4 Lactobacillus individually, the production of GABA was less than $0.1 \mathrm{~g} / \mathrm{L}$. Consequently, the high production of GABA was due to the promoted activity of $S$. thermophilus GABA. According to the production of GABA enhanced by organic nitrogen source (Figure 3 ). We speculated that the enhancement may be due to the milk protein peptide hydrolyzed by Lactobacillus or other small promoter molecules such as formic acid, pyruvate, folate, and ornithine secreted by Lactobacillus.

Table 3 lists the other GABA-enriched fermented products generated using GABA-producing LAB strains as starter cultures. Notably, S. thermophilus GABA exhibited superior production and productivity when compared with other LAB. Additionally, $\mathrm{CH}$ supplementation and coculture technology increased 
Table 2. Lactobacillus cocultured with Streptococcus thermophilus $\gamma$-aminobutyric acid (GABA) for $48 \mathrm{~h}$

\begin{tabular}{|c|c|c|c|c|c|}
\hline Strain & $\mathrm{pH}$ & $\begin{array}{c}\text { Titration acidity } \\
\quad\left({ }^{\circ} \mathrm{T} \pm \mathrm{SD}\right)\end{array}$ & $\begin{array}{l}\text { Production } \\
(\mathrm{g} / \mathrm{L} \pm \mathrm{SD})\end{array}$ & \multicolumn{2}{|c|}{$\mathrm{cfu} / \mathrm{mL}$} \\
\hline Streptococcus thermophilus & 4.62 & $117 \pm 10$ & $2.3 \pm 0.2$ & & $2.1 \times 10^{9}$ \\
\hline Lactobacillus rhamnosus & 4.46 & $141 \pm 10$ & $8.3 \pm 0.6$ & $2.8 \times 10^{9}$ & $2.1 \times 10^{9}$ \\
\hline Lactobacillus helveticus & 3.78 & $326 \pm 20$ & $5.2 \pm 0.4$ & $6.1 \times 10^{2}$ & $6.2 \times 10^{7}$ \\
\hline Lactobacillus paracasei & 4.01 & $163 \pm 10$ & $6.2 \pm 0.4$ & $2.5 \times 10^{9}$ & $2.1 \times 10^{9}$ \\
\hline
\end{tabular}

the production of GABA to a level comparable to that achieved by LAB cultured in synthetic nutrient broth medium. The use of $S$. thermophilus GABA as described in this work would yield fermented milk with a GABA concentration of $8.3 \mathrm{mg} / \mathrm{mL}$ after $48 \mathrm{~h}$ of fermentation. The ingestion of 1 unit $(100 \mathrm{~mL})$ of this fermented milk would provide the consumer with $830 \mathrm{mg}$ of GABA, which exceeds the bioactivity threshold previously reported to yield health benefits.

In human patients with hypertension, the daily intake of fermented milk containing $10 \mathrm{mg}$ of GABA for 12 wk was shown to decrease blood pressure by 17.4 $\mathrm{mmHg}$ (Inoue et al., 2003). Another study tested the effect of a naturally GABA-enriched Cheddar cheese on blood pressure levels in men with mild hypertension. In that study, a GABA-producing Lactococcus lactis ssp. lactis strain was used as the starter for experimental cheese production. The test group consumed $50 \mathrm{~g}$ of the experimental cheese, which contained $16 \mathrm{mg}$ of GABA, for $12 \mathrm{wk}$, and exhibited decreases in the mean and systolic blood pressure of $3.5 \pm 2.8$ and $5.5 \pm 3.9 \mathrm{mmHg}$, respectively. For comparison, the placebo group exhibited corresponding decreases of $1.6 \pm 3.0$ and $3.6 \pm$ $4.0 \mathrm{mmHg}$, respectively (Pouliot-Mathieu et al., 2013). Another previous study reported that the daily oral administration of $26.4 \mathrm{mg}$ of GABA derived from rice germ could treat neurological disorders effectively (Okada et al., 2000). Moreover, streptozotocin-induced diabetic mice were orally administered GABA-rich yogurt for 6 wk, and the results showed that oral administration of GABA-rich yogurt improved both hyperglycaemia and impaired glucose tolerance of streptozotocin-induced diabetic mice in a dose-dependent manner. Notably, GABA-rich yogurt led to significant decreases in the concentrations of serum total cholesterol (TC) and triacylglycerol (TG) and remarkable increases in the concentrations of high-density lipoprotein cholesterol and insulin in these mice (Chen et al., 2016). In the

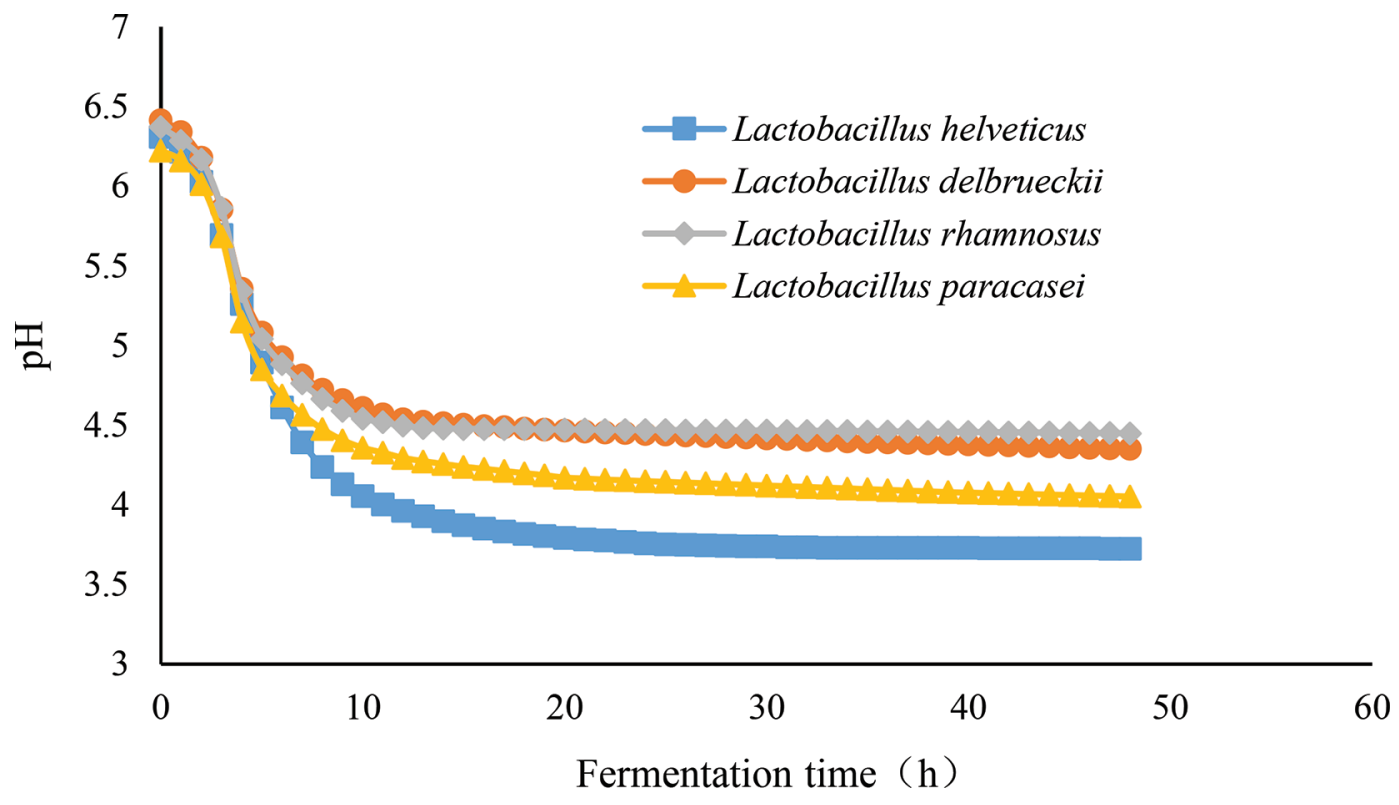

Figure 4. The acid response curves of Lactobacillus helveticus $(\mathbf{\square})$, Lactobacillus delbrueckii $(\bullet)$, Lactobacillus rhamnosus $(\bullet)$, and Lactobacillus paracasei $(\boldsymbol{\Lambda})$ cocultured with Streptococcus thermophilus $\gamma$-aminobutyric acid (GABA). 
Table 3. Comparison of $\gamma$-aminobutyric acid (GABA) production by different lactic acid bacteria

\begin{tabular}{|c|c|c|c|}
\hline Strain & Culture medium & $\begin{array}{l}\text { Production and } \\
\text { fermentation time }\end{array}$ & Reference \\
\hline Lactobacillus helveticus & Milk with monosodium glutamate (MSG) & $165.1 \mathrm{mg} / \mathrm{L}, 30 \mathrm{~h}$ & Sun et al., 2009 \\
\hline $\begin{array}{l}\text { Lactococcus lactis DIBCA1 and } \\
\text { Lactococcus plantarum PU11 }\end{array}$ & Milk with MSG and $5 \mathrm{~g} / \mathrm{L}$ yeast extract & $144.5 \mathrm{mg} / \mathrm{L}, 48 \mathrm{~h}$ & Nejati et al., 2013 \\
\hline $\begin{array}{l}\text { Streptococcus thermophilus YI-B1 } \\
\text { and Lactococcus brevis } 145\end{array}$ & Milk with MSG & $314 \mathrm{mg} / \mathrm{L}, 24 \mathrm{~h}$ & Wu et al., 2015 \\
\hline S. thermophilus & Milk with MSG & $83-108 \mathrm{mg} / \mathrm{L}, 24 \mathrm{~h}$ & Brasca et al., 2016 \\
\hline L. lactis B & $\begin{array}{l}\text { Brown rice juice, germinated soybean juice, } \\
\text { and enzymolyzed skim milk was } 33: 58: 9 \text { (vol: } \\
\text { vol:vol) }\end{array}$ & $6.41 \mathrm{~g} / \mathrm{L}, 144 \mathrm{~h}$ & Lu et al., 2008 \\
\hline S. thermophilus GABA & Milk with $10 \mathrm{~g} / \mathrm{L}$ MSG & $\begin{array}{l}2.8 \mathrm{~g} / \mathrm{L}, 48 \mathrm{~h} \\
3.4 \mathrm{~g} / \mathrm{L}, 72 \mathrm{~h}\end{array}$ & This study \\
\hline S. thermophilus GABA & $\begin{array}{l}\text { Milk with } 15 \mathrm{~g} / \mathrm{L} \text { MSG, } 1 \mathrm{~g} / \mathrm{L} \text { casein } \\
\text { hydrolysate }\end{array}$ & $5.4 \mathrm{~g} / \mathrm{L}, 48 \mathrm{~h}$ & This study \\
\hline
\end{tabular}

food industry worldwide, health food manufacturers are interested in GABA-enriched products. For example, in China, By-health (Guangzhou) recommends the consumption of 2 supplemental tablets containing $260 \mathrm{mg}$ of GABA each day. In the United States, Now (Bloomingdale, IL), Puritan's Pride (New York, NY), and GNC (Pittsburgh, PA) recommend the consumption of one 750-mg GABA tablet each day. The demonstrated production of GABA in this study provides sufficient proof that optimized use of $S$. thermophilus GABA in the production of fermented milk can result in suitable bioactive concentrations of GABA in the final product.

\section{CONCLUSIONS}

The $S$. thermophilus GABA strain described herein enables the natural in situ production of bioactive GABA-enriched fermented milk. Additionally, the conditions for GABA-enriched yogurt production have been optimized. The GABA production yield increased up to $8.3 \mathrm{~g} / \mathrm{L}$ in the presence of $15 \mathrm{~g} / \mathrm{L}$ MSG and in coculture with L. rhamnosus during a 48-h fermentation. This paper provides a foundation for the production of GABA-enriched functional foods.

\section{ACKNOWLEDGMENTS}

This work was supported by Funding for Training Young Teachers in Shanghai Universities (2019; China), Researches on Key Technologies of Probiotic Fermentation and Freeze-Drying (Shanghai Business School 18KY-PQMX-02; China), and Application Un- dergraduate Construction Project of Shanghai Municipal Universities (6th batch; China).

\section{REFERENCES}

Abdou, A. M., S. Higashiguchi, K. Horie, M. Kim, H. Hatta, and H. Yokogoshi. 2006. Relaxation and immunity enhancement effects of $\gamma$-Aminobutyric acid (GABA) administration in humans. Biofactors $26: 201$

Brasca, M., J. A. Hogenboom, S. Morandi, V. Rosi, P. D'Incecco, T. Silvetti, and L. Pellegrino. 2016. Proteolytic activity and production of $\gamma$-aminobutyric acid by Streptococcus thermophilus cultivated in microfiltered pasteurized milk. J. Agric. Food Chem. 64:8604-8614.

Chen, L., H. Zhao, C. Zhang, Y. Lu, X. Zhu, and Z. Lu. 2016. $\gamma$-Aminobutyric acid-rich yogurt fermented by Streptococcus salivarius ssp. thermophiles fmb5 appears to have anti-diabetic effect on streptozotocin-induced diabetic mice. J. Funct. Foods 20:267275.

Dave, R. I., and N. P. Shah. 1998. Ingredient supplementation effects on viability of probiotic bacteria in yogurt. J. Dairy Sci. 81:2804.

Di Cagno, R., F. Mazzacane, C. G. Rizzello, A. M. De, G. Giuliani, M. Meloni, S. B. De, and M. Gobbetti. 2010. Synthesis of gamma-aminobutyric acid (GABA) by Lactobacillus plantarum DSM19463: Functional grape must beverage and dermatological applications. Appl. Microbiol. Biotechnol. 86:731.

Dyke, K., S. E. Pépés, C. Chen, S. Kim, H. P. Sigurdsson, A. Draper, M. Husain, P. Nachev, P. A. Gowland, and P. G. Morris. 2017. Comparing GABA-dependent physiological measures of inhibition with proton magnetic resonance spectroscopy measurement of GABA using ultra-high-field MRI. Neuroimage 152:360.

Han, X., L. Zhang, P. Yu, H. Yi, and Y. C. Zhang. 2014. Potential of LAB starter culture isolated from Chinese traditional fermented foods for yoghurt production. Int. Dairy J. 34:247-251.

Haque, A., R. K. Richardson, and E. R. Morris. 2001. Effect of fermentation temperature on the rheology of set and stirred yogurt. Food Hydrocoll. 15:593-602.

Hayakawa, K., M. Kimura, K. Kasaha, K. Matsumoto, H. Sansawa, and Y. Yamori. 2004. Effect of a gamma-aminobutyric acidenriched dairy product on the blood pressure of spontaneously hypertensive and normotensive Wistar-Kyoto rats. Br. J. Nutr. 92:411. 
Inoue, K., T. Shirai, H. Ochiai, M. Kasao, K. Hayakawa, M. Kimura, and H. Sansawa. 2003. Blood-pressure-lowering effect of a novel fermented milk containing gamma-aminobutyric acid (GABA) in mild hypertensives. Eur. J. Clin. Nutr. 57:490-495.

Jakobs, C., J. Jaeken, and K. M. Gibson. 1993. Inherited disorders of GABA metabolism. J. Inherit. Metab. Dis. 16:704-715.

Khanal, S. N., and J. A. Lucey. 2018. Effect of fermentation temperature on the properties of exopolysaccharides and the acid gelation behavior for milk fermented by Streptococcus thermophilus strains DGCC7785 and St-143. J. Dairy Sci. 101:3799-3811. https://doi .org/10.3168/jds.2017-13203.

Komatsuzaki, N., J. Shima, S. Kawamoto, T. Kimura, and H. Momose. 2005. Production of $\gamma$-aminobutyric acid (GABA) by Lactobacillus paracase $i$ isolated from traditional fermented foods. Food Microbiol. 22:497-504.

Li, H., and Y. S. Cao. 2010. Lactic acid bacterial cell factories for gamma-aminobutyric acid. Amino Acids 39:1107-1116.

Linares, D. M., T. F. O'Callaghan, P. M. O'Connor, R. P. Ross, and C. Stanton. 2016. Streptococcus thermophilus APC151 strain is suitable for the manufacture of naturally GABA-enriched bioactive yogurt. Front. Microbiol. 7:1876.

Lu, X., Z. Chen, Z. Gu, and Y. Han. 2008. Isolation of $\gamma$-aminobutyric acid-producing bacteria and optimization of fermentative medium. Biochem. Eng. J. 41:48-52.

Nejati, F., C. G. Rizzello, R. Di Cagno, M. Sheikh-Zeinoddin, A. Diviccaro, F. Minervini, and M. Gobbetti. 2013. Manufacture of a functional fermented milk enriched of Angiotensin-I Converting Enzyme (ACE)-inhibitory peptides and $\gamma$-amino butyric acid (GABA). Lebensm. Wiss. Technol. 51:183-189.

Okada, T., T. Sugishita, T. Murakami, H. Murai, T. Saikusa, T. Horino, A. Onoda, O. Kajimoto, R. Takahashi, and T. Takahashi. 2000. Effect of the defatted rice germ enriched with GABA for sleeplessness, depression, autonomic disorder by oral administration. Nippon Shokuhin Kagaku Kogaku Kaishi 47:596-603.

Pouliot-Mathieu, K., C. Gardner-Fortier, S. Lemieux, D. St-Gelais, C. P. Champagne, and J. C. Vuillemard. 2013. Effect of cheese containing gamma-aminobutyric acid-producing lactic acid bacteria on blood pressure in men. PharmaNutrition 1:141-148.

Sanchart, C., O. Rattanaporn, D. Haltrich, P. Phukpattaranont, and S. Maneerat. 2017. Enhancement of gamma-aminobutyric acid (GABA) levels using an autochthonous Lactobacillus futsaii CS3 as starter culture in Thai fermented shrimp (Kung-Som). World J. Microbiol. Biotechnol. 33:152.

Sieuwerts, S., D. Molenaar, S. A. van Hijum, M. Beerthuyzen, M. J. Stevens, P. W. Janssen, C. J. Ingham, F. A. de Bok, W. M. de
Vos, and V. H. V. Je. 2010. Mixed-culture transcriptome analysis reveals the molecular basis of mixed-culture growth in Streptococcus thermophilus and Lactobacillus delbrueckii. Appl. Environ. Microbiol. 76:7775.

Skinner, F. A., R. J. Roughley, and M. R. Chandler. 2010. Effect of yeast extract concentration on viability and cell distortion in $R$ hizobium spp. J. Appl. Microbiol. 43:287-297.

Sun, T. S., S. P. Zhao, H. K. Wang, C. K. Cai, Y. F. Chen, and H. Zhang. 2009. ACE-inhibitory activity and gamma-aminobutyric acid content of fermented skim milk by Lactobacillus helveticus isolated from Xinjiang koumiss in China. Eur. Food Res. Technol. 228:607-612.

Suwanmanon, K., and P. C. Hsieh. 2014. Effect of $\gamma$-aminobutyric acid and nattokinase-enriched fermented beans on the blood pressure of spontaneously hypertensive and normotensive Wistar-Kyoto rats. J. Food Drug Anal. 22:485-491.

Syu, K. Y., C. L. Lin, H. C. Huang, and J. K. Lin. 2008. Determination of theanine, GABA, and other amino acids in green, oolong, black, and $\mathrm{Pu}$-erh teas with dabsylation and high-performance liquid chromatography. J. Agric. Food Chem. 56:7637-7643.

Watanabe, N., and N. Washio. 2011. Dietary-aminobutyric acid shortens the life span of stroke-prone spontaneously hypertensive rats. Food Nutr. Sci. 2:301-303.

Wong, C. G., T. Bottiglieri, and S. O. Rd. 2003. GABA, gamma-hydroxybutyric acid, and neurological disease. Ann. Neurol. 54(Supplement 6):3-12.

Wu, Q., Y.-S. Law, and N. P. Shah. 2015. Dairy Streptococcus thermophilus improves cell viability of Lactobacillus brevis NPSQW-145 and its $\gamma$-aminobutyric acid biosynthesis ability in milk. Sci. Rep. 5:12885.

Yang, S. Y., F. X. Lü, Z. X. Lu, X. M. Bie, Y. Jiao, L. J. Sun, and B. Yu. 2008. Production of $\gamma$-aminobutyric acid by Streptococcus salivarius ssp. thermophilus Y2 under submerged fermentation. Amino Acids 34:473-478.

Yokoyama, S., J. Hiramatsu, and K. Hayakawa. 2002. Production of gamma-aminobutyric acid from alcohol distillery lees by Lactobacillus brevis IFO-12005. J. Biosci. Bioeng. 93:95-97.

\section{ORCIDS}

Mei Han $\odot$ https://orcid.org/0000-0001-6155-3205

Chen Bai ๑ https://orcid.org/0000-0003-0491-6414 